\title{
Variant type of leiomyomas: 13 years of experience in a single institution
}

\author{
Besim Haluk Bacanakgil@, Gülşah IIhan®, Işık Kaban®® \\ Department of Obstetics and Gynegology, Health Science University, İstanbul Training and Research Hospital, Turkey
}

\begin{abstract}
Objectives: Our understanding of a variant type of leiomyoma lags far behind of leiomyoma/leiomyosarcoma of the uterus. The rarity of variant type leiomyomas limits epidemiologic study, evidence-based guidance for diagnosis and treatment. We aimed to analyze clinical, pathologic and radiological features of variant type of leiomyomas in women who underwent surgical therapy for symptomatic disease in a tertiary center. We furthermore intended to put forth the recurrence patterns of variant type of leiomyoma after uterine-conserving therapies.

Material and methods: Pathology results and inpatient files of women undergoing surgery (vaginal or abdominal hysterectomy; total abdominal hysterectomy and bilateral salphingoopherectomy; abdominal myomectomy; polipectomy) for symptomatic disease and with a histologic diagnosis of variant type of leiomyoma were assessed. Patient gravida, parity, menopausal status, patient complaint, type of initial surgical procedure, size of neoplasms, number of mitosis, presence of atypia, and necrosis, MRI evaluation, recurrence and any subsequent therapy were documented.

Results: A total of 3275 patients' medical records were evaluated between 2005-2018. The study sample comprised of 185 women with a diagnosis of variant type of leiomyoma. The patients ranged from 23 to 79 years of age. One hundred thirty-five cases were postmenopausal and 50 cases were during the reproductive period. The most common presenting symptom was menometrorrhagia (38.9\%). Four point nine percent of cellular leiomyoma, $14.2 \%$ of smooth muscle tumors of uncertain malignant potential (STUMP) and $4.7 \%$ of atypical leiomyomas were recurred with clinical follow-up.

Conclusions: Clinicians should be aware of variant type leiomyomas and their associated clinical, imaging, and pathologic issues.
\end{abstract}

Key words: leiomyoma; leiomyosarcoma; recurrence; variant type of leiomyoma

Ginekologia Polska 2022; 93, 6: 444-449

\section{INTRODUCTION}

Uterine leiomyoma and leiomyosarcoma are at opposite poles of the pathologic spectrum of uterine smooth muscle tumors. In between, there are variant type of leiomyomas including mitotically active leiomyoma, cellular leiomyoma, lipoleiomyoma, atypical leiomyoma, angiolipoleiomyoma and smooth muscle tumors of uncertain malignant potential (STUMP) [1-6].

Leiomyomas are benign smooth muscle tumours and are the most common solid tumors in women with an estimated incidence of 70\% [7]. Variant type of leiomyomas were relatively less and it is important to differentiate them from malignant neoplasms of the myometrium, since they have a good prognosis. Variant type of leiomyomas exhibit the same symptoms and signs as usual leiomyomas. Most variant type of leiomyomas present as typical fibroids and are excised if they are symptomatic. A woman with a uterine mass presumed to be a myoma is found to have a variant type of leiomyoma at pathologic analysis, with approximately 10 in 100 cases [8]. The rarity of this diagnosis limits epidemiologic study, evidence-based guidance for diagnosis and treatment. Most variant types of leimyomas are restricted to case reports and small case series. There are no imaging modalities that can distinguish histologic variants from other leiomyomas. They are diagnosed by pathology examination following myomectomy or hysterectomy.

Our understanding of a variant type of leiomyoma lags far behind of leiomyosarcoma/leiomyosarcoma of the uterus. The recurrence risk of variant type of leiomyoma has never been fully characterized because of the use of hysterectomy as the primary therapeutic option. However, the evolution of uterus preserving surgeries require un-

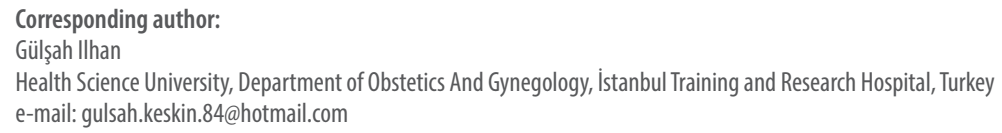


derstanding of the pathophysiology, clinical phenotype and natural history of these lesions.

\section{Objectives}

Clinicians should be aware of variant typeleiomyomas and their associated clinical, imaging, and pathologic issues. The aim of this study was to analyze clinical, pathologic and radiological features of variant type of leiomyomas in women who underwent surgical therapy for symptomatic disease in a tertiary center. We furthermore intended to put fort the recurrence patterns of variant type of leiomyoma after uterine-conserving therapies.

\section{MATERIAL AND METHODS}

Medical records between 2005-2018 of Department of Obstetrics and Gynecology at Health Science University, Istanbul Training and Research Hospital, a tertiary center, were retrospectively evaluated. Pathology results and inpatient files of women undergoing surgery (vaginal or abdominal hysterectomy; total abdominal hysterectomy and bilateral salphingoopherectomy; abdominal myomectomy; polipectomy) for symptomatic disease and with a histologic diagnosis of variant type of leiomyoma were assessed. Patients with histopathological diagnosis of mitotically active leiomyoma, cellular leiomyoma, lipoleiomyoma, atypical leiomyoma, angiolipoleiomyoma, vascular leiomyoma, myxoid leiomyoma and STUMP were included. The following data were documented: patient gravida, parity, menopausal status, patient complaint, type of initial surgical procedure, size of neoplasms, number of mitosis, presence of atypia, and necrosis, magnetic resonance imaging (MRI) evaluation, recurrence and any subsequent therapy. Tumor size was based on gross pathology. The histologic features including presence of atypical cells, overall cellularity, mitotic index defined as the highest number of mitotic figures (MF) counted in 10 high-power fields (HPF), presence and type of necrosis were recorded.

Dysmenorrhea, menorrhagia, menometrorrhagia, pelvic pain, pelvic mass, vaginal discharge, postmenopausal bleeding and prolapsus were considered to be presenting symptoms. Premenopausal status was defined as the occurrence of at least one menstrual period in the 12 months before surgery. Patients who had a concomitant gynecologic cancers were excluded from the study.

\section{Statistical analysis}

IBM SPSS Statistics 22.0 program was used for statistical analysis. Descriptive statistical methods (mean, standard deviation) were used. Qualitative data were compared using the Chi-Square test. Significance was evaluated at $p<0.05$.

\section{RESULTS}

A total of 3275 patients' medical records were evaluated between 2005-2018. Our study sample comprised of 185 women with a diagnosis of variant type of leiomyoma (102 cellular leiomyomas, 32 lipoleiomyomas, 21 atypical leiomyomas, 8 mitotically active leiomyomas, 7 STUMP, 5 myxoid leiomyomas, 5 angiomyolipomas, 5 vascular leiomyomas).

The surgical procedures of the cohort consisted of 110 total abdominal hysterectomies and bilateral salphingo-oopherectomies, 39 abdominal myomectomies, 24 total abdominal hysterectomies, 5 polypectomies, and 3 vaginal hysterectomies. Demographic features of patients were given in Table 1. The patients ranged from 23 to 79 years of age (mean age $47.80 \pm 11.29$ ). One hundred thirty-five cases

\begin{tabular}{|c|c|c|c|}
\hline & & $\mathbf{n}$ & $\%$ \\
\hline \multirow{2}{*}{ Gravida } & $<5$ & 120 & 64.9 \\
\hline & $\geq 5$ & 65 & 35.1 \\
\hline \multirow{2}{*}{ Parity } & $<5$ & 163 & 88.1 \\
\hline & $\geq 5$ & 22 & 11.9 \\
\hline \multirow{2}{*}{$\begin{array}{l}\text { Menopausal } \\
\text { status }\end{array}$} & Premenopause & 135 & 73 \\
\hline & Postmenopause & 50 & 27 \\
\hline \multirow{8}{*}{$\begin{array}{l}\text { Presenting } \\
\text { symptom }\end{array}$} & Vaginal discharge & 2 & 1.1 \\
\hline & Menorrhagia & 21 & 11.3 \\
\hline & Menometrorrhagia & 72 & 38.9 \\
\hline & Menorrhagia and dysmenorrhea & 23 & 12.4 \\
\hline & Pelvic pain & 44 & 23.8 \\
\hline & Pelvic pain and mass & 1 & 0.5 \\
\hline & Pelvik pain and prolapsus & 3 & 1.6 \\
\hline & Postmenopausal bleeding & 19 & 10.3 \\
\hline \multirow{5}{*}{ Operation } & $\mathrm{TAH}+\mathrm{BSO}$ & 110 & 59.5 \\
\hline & $\mathrm{TAH}$ & 24 & 13 \\
\hline & Myomectomy & 39 & 23.2 \\
\hline & Polipectomy & 5 & 2.7 \\
\hline & VAH & 3 & 1.6 \\
\hline \multirow{8}{*}{ Diagnosis } & Angiolipoleiomyom & 5 & 2.7 \\
\hline & Atypical leiomyom & 21 & 11.4 \\
\hline & Lipoleiomyom & 32 & 17.3 \\
\hline & Myxoid leiomyom & 5 & 2.7 \\
\hline & Mitotically active & 8 & 4.3 \\
\hline & Cellular leiomyom & 102 & 55.1 \\
\hline & STUMP & 7 & 3.8 \\
\hline & Vascular leiomyom & 5 & 2.7 \\
\hline
\end{tabular}

$\mathrm{n}$ - number; TAH - total abdominal hysterectomy; BSO - bilateral salphingoopherectomy; STUMP - smooth muscle tumors of uncertain malignant potential 
were post menopausal, 50 cases were in reproductive period. The most common presenting symptom was menometrorrhagia ( $\mathrm{n:} 72,38.9 \%$ ), followed by pelvic pain ( $\mathrm{n}: 44,23.8 \%$ ).

Distribution of tumor characteristics were given in Table 2. The size of the variant type of leiomyoma ranged from $2 \mathrm{~cm}$ to $26 \mathrm{~cm}$, with a median of $8 \mathrm{~cm}$. By the highest count method, 140 cases were found to have $0 \mathrm{MF} / 10 \mathrm{HPF}$, 23 showed 1 to $3 \mathrm{MF} / 10 \mathrm{HPF}$, and 22 cases were found to have $\geq 3$ MF/10HPF. While 29 (15.7\%) of the cases had atypia, $156(84.3 \%)$ had no atypia. The necrosis was observed in 9 (4.9\%) of the cases and not observed in 176 (95.1\%). One hundred seventy-nine $(96.75 \%)$ of tumors affected the uterine corpus, and 6 (3.25\%) was in the cervix uteri.

Thirty-six of the patients had MRI evaluations. Eighty-three point three percent of cases showed hypointensity on $\mathrm{T} 1$ weighted images, $75 \%$ of cases showed hyperintensity on T2 weighted images, $66.7 \%$ of the cases had positive fat substraction and all of the 36 cases showed contrast enhancement.

None of mitotically active leiomyomas, lipoleiomyoma, myxoid leiomyomas, angiomyolipomas and vascular leiomyomas were recurred; however, 5 of 102 (4.9\%) cellular leiomyomas and one of 21 (4.7\%) atypical leiomyoma were recurred during clinical follow-up.

Evaluation of clinical parameters according to pathologic diagnosis were given in Table 3. There was a statistically significant difference between the number of gravida and parity according to diagnosis $(p<0.01)$. The incidence of myxoid leiomyoma and STUMP were higher in cases with gravida and parity number $\geq 5$. Angiolipoleiomyoma was not observed in patients with gravida number $\geq 5$. Angi- olipoleiomyoma, mitotically active leiomyoma and vascular leiomyoma were not observed in patients with parity number $\geq 5$.

\begin{tabular}{|c|c|c|c|}
\hline & & Min-Max & $\begin{array}{l}\text { Mean } \pm \text { SD } \\
\text { (median) }\end{array}$ \\
\hline \multirow{2}{*}{$\begin{array}{l}\text { Tumor diameter } \\
\text { (cm) }\end{array}$} & & $2-26$ & $8.55 \pm 5.21(8)$ \\
\hline & & $\mathrm{N}$ & $\%$ \\
\hline \multirow{4}{*}{ Number of mitosis } & 0 & 140 & 75.7 \\
\hline & 1 & 15 & 8.1 \\
\hline & 2 & 8 & 4.3 \\
\hline & $\geq 3$ & 22 & 11.9 \\
\hline \multirow{2}{*}{ Atypia } & - & 156 & 84.3 \\
\hline & + & 29 & 15.7 \\
\hline \multirow{2}{*}{ Necrosis } & - & 176 & 95.1 \\
\hline & + & 9 & 4.9 \\
\hline \multirow{2}{*}{$T 1(n=36)$} & Isointense & 6 & 16.7 \\
\hline & Hypointense & 30 & 83.3 \\
\hline \multirow{3}{*}{ T2 (n = 36) } & Isointense & 1 & 2.8 \\
\hline & Hypointense & 8 & 22.2 \\
\hline & Hyperintense & 27 & 75 \\
\hline \multirow{2}{*}{$\begin{array}{l}\text { Fat substraction } \\
(n=36)\end{array}$} & - & 24 & 66.7 \\
\hline & + & 12 & 33.3 \\
\hline $\begin{array}{l}\text { Contrast } \\
\text { enhancement } \\
(n=36)\end{array}$ & + & 36 & 100 \\
\hline
\end{tabular}

$\mathrm{n}$ - number; SD - standard deviation

Tablo 3. Evaluation of clinical parameters according to pathologic diagnosis

\begin{tabular}{|c|c|c|c|c|c|c|c|c|}
\hline & $\begin{array}{l}\text { Angiolipolei- } \\
\text { omyoma }\end{array}$ & $\begin{array}{l}\text { Atypical } \\
\text { leiomyoma }\end{array}$ & $\begin{array}{l}\text { Lipoleio- } \\
\text { myoma }\end{array}$ & $\begin{array}{l}\text { Miksoid } \\
\text { leiomyoma }\end{array}$ & $\begin{array}{l}\text { Mitotically active } \\
\text { leiomyoma }\end{array}$ & $\begin{array}{l}\text { Cellular } \\
\text { leiomyoma }\end{array}$ & STUMP & $\begin{array}{l}\text { Vascular } \\
\text { Leiomyoma }\end{array}$ \\
\hline & $\mathbf{n} ; \%$ & $\mathbf{n} ; \%$ & $\mathbf{n} ; \%$ & $\mathbf{n} ; \%$ & $\mathbf{n} ; \%$ & $\mathbf{n} ; \%$ & $\mathbf{n} ; \%$ & $\mathrm{n} ; \%$ \\
\hline${ }^{* *}$ Gravida $\geq 5$ & $0 ; 0$ & $8 ; 38.1$ & $14 ; 43.8$ & $5 ; 100$ & $3 ; 37.5$ & $26 ; 25.5$ & $7 ; 100$ & $2 ; 40$ \\
\hline **Parity $\geq 5$ & $0 ; 0$ & $1 ; 4.8$ & $5 ; 15.6$ & $5 ; 100$ & $0 ; 0$ & $4 ; 3.9$ & $7 ; 100$ & $0 ; 0$ \\
\hline **Tumor Diameter $\geq 10$ & $0 ; 0$ & $2 ; 9.5$ & $6 ; 18.8$ & $5 ; 100$ & $0 ; 0$ & $22 ; 21.6$ & $7 ; 100$ & $3 ; 60$ \\
\hline **Menometrorrhagia & $5 ; 100$ & $7 ; 33.3$ & $10 ; 31.3$ & $0 ; 0$ & $6 ; 75$ & $42 ; 41.2$ & $0 ; 0$ & $2 ; 40$ \\
\hline TAH + BSO & $0 ; 0$ & $11 ; 52.4$ & $22 ; 68.8$ & $5 ; 100$ & $5 ; 62.5$ & $56 ; 54.9$ & $7 ; 100$ & $4 ; 80$ \\
\hline ТАH & $0 ; 0$ & $2 ; 9.5$ & $3 ; 9.4$ & $0 ; 0$ & $2 ; 25$ & $16 ; 15.7$ & $0 ; 0$ & $1 ; 20$ \\
\hline Myomectomy & $5 ; 100$ & $7 ; 33.3$ & $4 ; 12.5$ & $0 ; 0$ & $1 ; 12.5$ & $26 ; 25.5$ & $0 ; 0$ & $0 ; 0$ \\
\hline Polipectomy & $0 ; 0$ & $0 ; 0$ & $2 ; 6.3$ & $0 ; 0$ & $0 ; 0$ & $3 ; 2.9$ & $0 ; 0$ & $0 ; 0$ \\
\hline VAH & $0 ; 0$ & $1 ; 4.8$ & $1 ; 3.1$ & $0 ; 0$ & $0 ; 0$ & $1 ; 1$ & $0 ; 0$ & $0 ; 0$ \\
\hline$* *$ Mitosis $\geq 3$ & $0 ; 0$ & $2 ; 9.5$ & $0 ; 0$ & $0 ; 0$ & $5 ; 62.5$ & $8 ; 7.8$ & $7 ; 100$ & $0 ; 0$ \\
\hline **Atypia & $0 ; 0$ & $16 ; 76.2$ & $0 ; 0$ & $0 ; 0$ & $0 ; 0$ & $6 ; 5.9$ & $7 ; 100$ & $0 ; 0$ \\
\hline **Necrosis & $0 ; 0$ & $1 ; 4.8$ & $0 ; 0$ & $0 ; 0$ & $0 ; 0$ & $1 ; 1$ & $7 ; 100$ & $0 ; 0$ \\
\hline
\end{tabular}

$\mathrm{Ki}$ - Kare test was used; ** $\mathrm{p}<0.01 ; \mathrm{n}$ - number; TAH — total abdominal hysterectomy; BSO — bilateral salphingoopherectomy; $\mathrm{VAH}$ — vaginal hysterctomy; STUMP — smooth muscle tumors of uncertain malignant potential 
There was a statistically significant difference between tumor diameters according to diagnosis $(p<0.01)$. The incidence of myxoid leiomyoma, STUMP and vascular leiomyoma were higher in patients with tumor diameter of $\geq 10 \mathrm{~cm}$. Angiolipoleiomyoma and mitotically active leiomyoma were not observed in those patients.

There was a statistically significant difference between menometrorrhagia symptom according to diagnosis $(p<0.01)$. The incidence of angiolipoleiomyoma was higher in patients with menometrorrhagia than other diagnoses. Myxoid leiomyoma and STUMP diagnoses were not observed in those patients.

There was a statistically significant difference between the number of mitosis according to diagnosis $(p<0.01)$. The incidence of mitotically active leiomyoma and STUMP were higher in cases with mitosis number $\geq 3$. Angiolipoleiomyoma, lipoleiomyoma, myxoid leiomyoma and vascular leiomyoma were not observed in those patients.

There was a statistically significant difference between the presence of atypia according to diagnosis $(p<0.01)$. The incidence of atypical leiomyoma and STUMP were higher in patients with atypia. Angiolipoleiomyoma, lipoleiomyoma, myxoid leiomyoma and vascular leiomyoma were not observed in those patients.

There was a statistically significant difference between the presence of necrosis according to the diagnosis $(p<0.01)$. The incidence of STUMP was higher in patients with necrosis compared to other diagnoses. Angiolipoleiomyoma, lipoleiomyoma, myxoid leiomyoma and vascular leiomyoma were not observed in those patients.

\section{DISCUSSION}

In the present study, we aimed to reveal our 13 year clinical experince of variant type of leiomyomas. Since variant type of leiomyomas have a greater risk for recurrence than benign leiomyomas, careful analysis of clinical and pathological features will help treatment planning and follow-up strategies.

Variant type of leiomyomas were relatively less, but it is important to differentiate them from malignant neoplasms of the myometrium, as they have good prognosis. Tumor size, presence or absence of necrosis, cytological atypia and vascular invasion, nature of tumor margins are most important histological features for differentiation. Variant type of leiomyomas include mitotically active leiomyoma, cellular leiomyoma, lipoleiomyoma, atypical leiomyoma, angiolipoleiomyoma, vascular leiomyoma, myxoid leiomyoma and smooth muscle tumors of uncertain malignant potential (STUMP) [1-6].

Cellular leiomyoma constitues $5 \%$ of leiomyomas. The clinical data on cellular leiomyoma are scanty. The recurrence rate after myomectomy is $8-12 \%$ for patients underwent myomectomy $[9,10]$. They have increased cellularity compared to the adjacent myometrium [7, 11,12]. The disease is often considered benign but should not be considered as having a completely benign course. Hysterectomy is an option for patients who do not wish to preserve their fertility. Women who wish to retain fertility deserve a close follow-up. Close follow-up is also recommended even if total hysterectomy has been performed because disease recurrence, metastases and malignant transformations can occur even after 10 years $[13,14]$. In our study, $55.1 \%$ of variant type of leiomyoma cases were cellular leiomyoma. Four point eighty-eight percent of cellular leiomyomas originated from cervix uteri. The rest of the cases originated from corpus uteri. One of the cases diagnosed as cellular leiomyoma after myomectomy procedure was presented with a mass two years later and hysterectomy was performed. The pathological diagnosis was leiomyoma. Another mass at the pelvis with a diameter of $4 \mathrm{~cm}$ was detected at the same patient two years following second operation. The pathological result of pelvic mass was cellular leiomyoma.

Two cases with cellular leiomyoma diagnosis were presented with mass three and eight years following first operations (myomectomy). Pathological examination of the materials were leiomyoma and adenomyosis. One other case with cellular leiomyoma recurred from the cervix uteri with a diameter of $6 \mathrm{~cm}$ five years after myomectomy, was hysterectomized and pathology was cellular leiomyoma.

One of the cases had polipectomy. The histology was variant type of leiomyoma (cellular leiomyoma). Two years following first operation, the patient had another polipectomy procedure. The pathologic result was adenosarcoma with $3 \mathrm{~cm}$ diameter. Surgical staging was performed and the follow-ups were unremarkable.

Lipoleiomyomas are uncommon and their reported incidence constitutes 0.03 to $0.2 \%$ of benign uterine tumors $[15,16,17]$. Since most cases are not involved due to their benign behaviour and they show histological features of admixture of varying amounts of mature adipose tissue with smooth muscle cells, their exact incidence is unknown. These tumors usually occur in postmenopausal women between 50-75 years of age [17]. Cytological atypia, necrosis, and calcification were not seen. The mitotic rate was zero in all cases. In our study; the incidence was $17.3 \%$. Lipoleiomyomas sometimes are accompanied by anomalous blood vessels surrounded by smooth muscle cells and called angiomyolipoma [17]. In our case the $2.7 \%$ of the variant type of leiomyomas was angiomyolipoma. None of the lipoleiomyoma and angiomyolipoma cases were recurred.

Myxoid leiomyoma is consist of benign smooth muscle cells with myxoid material separating the tumor cells. The margins are circumscribed and neither cytological atypia nor mitotic figures are present. [18-20]. In our cohort; $2.7 \%$ 
of the variant type of leiomyomas was myxoid leiomyoma. None of them were recurred.

Mitotically active leiomyoma is defined as tumours having 5-15 mitoses/10 HPFs but lacking necrosis or cytological atypia. The clinical behaviour is like that of a benign neoplasm and may be seen in patients with pregnancy or taking exogenous hormones [11, 21]. In our cohort; $4.3 \%$ of the variant type leiomyomas was mitotically active leiomyoma and none of them was recurred.

Atypical leiomyoma shows the presence of atypical cells and demonstrates moderate-severe cytologic atypia [11]. They resemble leiomyosarcomas. Most noticeable marker is low mitotic activity and absence of necrosis [5]. Twenty-one (11.4\%) cases in our study, showed only nuclear atypia without necrosis or significant mitoses and hence were diagnosed as atypical leiomyoma. Five out of seven recurrent cases were cellular leiomyoma. Only one of the seven recurrent cases was atypical leiomyoma. The first operation was myomectomy and recurred after seven years. Myomectomy was performed again due to fertility preservation demand of the patient. The pathological result of second specimen was atypical leiomyoma.

Uterine smooth muscle tumor of uncertain malignant potential (STUMP) is a rare diagnosis. It is defined by the World Health Organization (WHO) as a smooth muscle tumor between benign and malignant criteria [5]. It is mostly seen in patients in their forties, who were operated with a leiomyoma diagnosis. Risk factors and prognosis are not exactly known, but there is risk of recurrence or metastasis in long term follow-up. The following histologic findings including a smooth muscle tumor with an uncertain type of necrosis, the presence of focal or diffuse cytologic atypia but the mitotic count is $<10 / 10 \mathrm{HPF}$, the presence of coagulative tumor necrosis but mitosis is $<10 / 10 \mathrm{HPF}$, and cellular tumors with $>15$ mitosis/10 HPF are frequently encountered [22]. A retrospective study of Dańska-Bidzińska et al., evaluated the clinical and pathological features and outcomes of ten patients diagnosed with STUMP. Uterine bleeding was the second most frequent symptom. They performed conservative procedure in three cases, whereas in other patients hysterectomy was performed. Diameter of the tumors ranged from 3 to $29 \mathrm{~cm}$. In all tumors mitoses were less than 10 per 10/hpf, atypia of middle or severe type, and in three cases necrosis was observed. They revealed no recurrence during the follow-up period [23]. In our study; $7(3.8 \%)$ of the variant type of leiomyomas was STUMP. Diameter of the tumors were $>10 \mathrm{~cm}$ in all cases. They all showed mitosis < 10/10 HPF, atypia and necrosis. Hysterectomy was performed in all seven patients. One of them (14.2\%) was recurred.

The exact diagnosis of a variant type of leiomyoma made with pathologic examination. But hypointense T1 signal intensity, moderate T2 signal intensity, hyperintensity on Diffusion-weighted imaging (DWI), if present, might raise the possibility of a leiomyoma variant [24]. In our sample, 36 of the patients had MRI evaluations. Eighty-three point three percent of cases showed hypointensity on T1 weighted image, $75 \%$ of cases showed hyperintensity on T2 weighted image, $66.7 \%$ of the cases had positive fat substraction and all of the 36 cases showed contrast enhancement.

In our study; $4.9 \%$ of cellular leiomyoma, $14.2 \%$ of STUMP and $4.7 \%$ of atypical leiomyomas were recurred with clinical follow-up. In the literature; Zhang et al., [25] reported that none of six mitotically active leiomyomas and none of 17 cellular leiomyomas were recurred. Three out of 31 atypical leiomyomas and three of 14 STUMP with clinical follow-up were recurred. Kim et al., [26] reported an isolated case of a mitotically active leiomyoma recurrence as a leiomyosarcoma. Taran et al., [13] reported two out of 99 patients with cellular leiomyomas (2\%) had recurrent disease. Studies in the literature suggest that atypical leiomyomas and uterine STUMPs may have a greater risk of recurrence [27-29].

\section{CONCLUSIONS}

Clinicians should be aware of variant type leiomyomas and their associated clinical, imaging, and pathologic issues. Understanding the diversity of variant type of leiomyoma in both pathology and symptomatology will lead to targeted therapy in the short term and prevention strategies in the long term in clinical practice. Since most variant type of leiomyomas mimic malignancy in one or more respects, diagnosis should be done by experienced pathologists due to the fact that they might be misdiagnosed. Though the frequency with which they occur remains less, their correct diagnosis was essential for a conservative management in patients wishing to preserve fertility.

Also, as we reveal, there is increasing evidence that variant type of leiomyomas may have recurrence potential. In clinical practice, the importance of exhaustive histopathological examination should be emphasized once again. Confirmed diagnosis is mandatory and has paramount importance for optimal management, and surveillance of the concerned patients. We emphasize on imperative submission of all hysterectomy specimens for histopathology, thorough sampling, and diligent quest for associated pathologies in routine hysterectomy specimens, few of which may need further management and surveillance for the patient's well-being. Early identification of these lesions may be beneficial for adequate treatment and follow-up. Prospective studies with longer follow-up would be important to gain insight into the pathogenesis of this subgroup of variant type of leiomyoma. 


\section{Acknowledgements}

None.

\section{Conflict of interests}

No conflict of interest.

\section{REFERENCES}

1. Rosai J. Female reproductive system. In: Rosai J, Ackerman LV. ed. Ackerman's Surgical Pathology. 7th ed. C.V. Mosby Company, St. Louis 1989: 997-1191.

2. Manjula K, Kadam SR, Chandrasekhar HR. Variants of Leiomyoma: Histomorphological Study of Tumors of Myometrium. JSAFOG. 2011; 3: 89-92

3. Mohammed A, Shehu SM, Ahmed SA et al. Uterine leiomyomata: a five year clinicopathological review in Zaria, Nigeria. Nigerian Journal of Surgical Research. 2006; 7(1), doi: 10.4314/njsr.v7i1.12281.

4. Nayak J, Prajapati V, Desai K, et al. Uterine leiomyoma: clinical profile at civil hospital, Ahmedabad. NJIRM. 2012; 3: 50-53.

5. Ibrar F, Riaz S, Dawood N. Frequency of fibroid uterus in multipara women in a tertiary care centre in Rawalpindi. J Ayub Med Coll. 2010; 22: 155-157.

6. Arleo EK, Schwartz PE, Hui $P$, et al. Review of leiomyoma variants. AJR Am J Roentgenol. 2015; 205(4): 912-921, doi: 10.2214/AJR.14.13946, indexed in Pubmed: 26397344.

7. Wilkinson N, Rollason TP. Recent advances in the pathology of smooth muscle tumours of the uterus. Histopathology. 2001; 39(4): 331-341, doi: 10.1046/j.1365-2559.2001.01300.x, indexed in Pubmed: 11683931.

8. Seidman MA, Oduyebo T, Muto MG, et al. Peritoneal dissemination complicating morcellation of uterine mesenchymal neoplasms. PLoS One. 2012; 7(11): e50058, doi: 10.1371/journal.pone.0050058, indexed in Pubmed: 23189178

9. Kang MW, Kang SK, Yu JH, et al. Benign metastasizing leiomyoma: metastasis to rib and vertebra. Ann Thorac Surg. 2011; 91(3): 924-926, doi: 10.1016/j.athoracsur.2010.08.030, indexed in Pubmed: 21353035.

10. Rothmund R, Kurth RR, Lukasinski NM, et al. Clinical and pathological characteristics, pathological reevaluation and recurrence patterns of cellular leiomyomas: a retrospective study in 76 patients. Eur J Obstet Gynecol Reprod Biol. 2013; 171(2): 358-361, doi: 10.1016/j. ejogrb.2013.10.004, indexed in Pubmed: 24176540.

11. Bell SW, Kempson RL, Hendrickson MR. Problematic uterine smooth muscle neoplasms. A clinicopathologic study of 213 cases. Am J Surg Pathol. 1994; 18(6): 535-558, indexed in Pubmed: 8179071.

12. Oliva E, Young RH, Clement PB, et al. Cellular benign mesenchymal tumors of the uterus. A comparative morphologic and immunohistochemical analysis of 33 highly cellular leiomyomas and six endometrial stromal nodules, two frequently confused tumors. Am J Surg Pathol. 1995; 19(7): 757-768, doi: 10.1097/00000478-199507000-00003, indexed in Pubmed: 7793473.

13. Taran FA, Weaver AL, Gostout BS, et al. Understanding cellular leiomyomas: a case control study. Fertility and Sterility. 2009; 92(3): S45, doi: 10.1016/j.fertnstert.2009.07.176.
14. Sharma $\mathrm{P}, \mathrm{Chaturvedi} \mathrm{KU}$, Gupta $\mathrm{R}$, et al. Leiomyomatosis peritonealis disseminata with malignant change in a post-menopausal woman. Gynecol Oncol. 2004; 95(3): 742-745, doi: 10.1016/j.ygyno.2004.09.007, indexed in Pubmed: 15581996.

15. Wang X, Kumar D, Seidman JD. Uterine lipoleiomyomas: a clinicopathologic study of 50 cases. Int J Gynecol Pathol. 2006; 25(3): 239-242, doi: 10.1097/01.pgp.0000192273.66931.29, indexed in Pubmed: 16810060.

16. Saumitra B, Sudipta C, Abantika K, et al. Lipoleiomyoma of uterus. The Journal of Obstetrics and Gynecology of India. 2010; 60(2): 160-161, doi: 10.1007/s13224-010-0025-0.

17. Aung $T$, Goto $M$, Nomoto $M$, et al. Uterine lipoleiomyoma: a histopathological review of 17 cases. Pathol Int. 2004; 54(10): 751-758, doi: 10.1111/j.1440-1827.2004.01748.x, indexed in Pubmed: 15482564.

18. Tavassoli FA, Deville P. eds. In: World Health Organization of Tumours. Pathology and genetics of tumours of the breast and female genital organs. Lyon: IARC Press. 2003: 236-242.

19. Sangle NA, Lele SM. Uterine mesenchymal tumors. Indian J Pathol Microbiol. 2011; 54(2): 243-253, doi: 10.4103/0377-4929.81582, indexed in Pubmed: 21623068.

20. Jaime Prat. Smooth muscle tumors of uterus Pathology . http://www uscap.org.

21. Boyd C, McCluggage WG. Unusual morphological features of uterine leiomyomas treated with progestogens. J Clin Pathol. 2011; 64(6): 485-489, doi: 10.1136/jcp.2011.089664, indexed in Pubmed: 21398323.

22. Dańska-Bidzińska A, Bakuła-Zalewska E, Nasierowska-Guttmejer A, et al. Smooth muscle tumor of uncertain malignant potential (STUMP)-clinico-pathomorphological analysis of the cases and literature review. Ginekol Pol. 2012; 83(6): 412-6.

23. Kurman RJ, Carcangiu ML, Herrington CS, Young RH. WHO classification of tumours of female reproductive organs, 4th ed. International Agency for Research on Cancer, Lyon 2014.

24. Tanaka YO, Nishida M, Tsunoda $\mathrm{H}$, et al. Smooth muscle tumors of uncertain malignant potential and leiomyosarcomas of the uterus: MR findings. J Magn Reson Imaging. 2004; 20(6): 998-1007, doi: 10.1002/jmri.20207, indexed in Pubmed: 15558559.

25. Zhang Q, Ubago J, Li Li, et al. Molecular analyses of 6 different types of uterine smooth muscle tumors: Emphasis in atypical leiomyoma. Cancer. 2014; 120(20): 3165-3177, doi: 10.1002/cncr.28900, indexed in Pubmed: 24986214

26. Kim JH, ChoiYJ, Kim DC, et al. Leiomyosarcoma arising in a patient with prior mitotically active leiomyoma. J Obstet Gynaecol Res. 2010; 36(1): 187-190, doi: 10.1111/j.1447-0756.2009.01117.x, indexed in Pubmed: 20178549.

27. Ly A, Mills AM, McKenney JK, et al. Atypical leiomyomas of the uterus: a clinicopathologic study of 51 cases. Am J Surg Pathol. 2013;37(5):643-649, doi: 10.1097/PAS.0b013e3182893f36, indexed in Pubmed: 23552381.

28. Guntupalli SR, Ramirez PT, Anderson ML, et al. Uterine smooth muscle tumor of uncertain malignant potential: a retrospective analysis. Gynecol Oncol. 2009; 113(3):324-326, doi: 10.1016/j.ygyno.2009.02.020, indexed in Pubmed: 19342083.

29. Ip PPC, Cheung ANY, Clement PB. Uterine smooth muscle tumors of uncertain malignant potential (STUMP): a clinicopathologic analysis of 16 cases. Am J Surg Pathol. 2009; 33(7): 992-1005, doi: 10.1097/PAS.0b013e3181a02d1c, indexed in Pubmed: 19417585. 